\title{
28 Research Square \\ Effect of National Basic Public Health Services On The Health of Internal Migrants in China
}

Liange Zhao

Zhejiang Gongshang University

hongbin yuan

Zhejiang Gongshang University

Xueyuan Wang ( $\nabla$ wxyrocky@163.com)

Zhejiang Gongshang University

Research

Keywords: National basic public health services, health, internal migrants, China

Posted Date: September 9th, 2021

DOI: https://doi.org/10.21203/rs.3.rs-861081/v1

License: (c) (7) This work is licensed under a Creative Commons Attribution 4.0 International License. Read Full License 


\section{Abstract \\ Objective}

This paper evaluates the effect of National Basic Public Health Services (NBPHS) on the health of internal migrants in China.

\section{Study design:}

The study design used in this research is a cross-sectional study.

\section{Methods}

Data were obtained from the China Migrants Dynamic Survey (CMDS) of 2017, including 150,384 internal migrants at the age of 15-59. Propensity score matching (PSM) was used to estimate the effect of NBPHS.

\section{Results}

The findings indicate that NBPHS is successful in improving the health of internal migrants. Different matching algorithms showed the improvement ranging from 2.7 to 2.9 percentage points for the indicator of self-reported health, compared with the reduction of the probability of having disease ranging from 3.3 to 3.7 percentage points in the past year. However, gains are not shared equally. Heterogeneity analysis found significant improvement in the health of patients with hypertension, but the health improvement of diabetics was relatively small. There was also no significant effect on patients with both hypertension and diabetes. Similarly, less improvement was observed in those over 65 years old.

\section{Conclusions}

This research suggests that policymakers should not only pay attention to the equalization of project implementation but also focus on narrowing the benefits gap between different groups of internal migrants. This finding highlights the importance of encouraging more young doctors to provide health services in primary institutions and promoting the sinking of high-quality medical resources.

\section{Introduction}

Universal Health Coverage (UHC) has been determined as a priority for the global health agenda [1]. A great number of countries have adopted UHC as an aspiration for national policy in the past few years [2]. In 2009, China initiated a new healthcare reform, and the Ministry of Health began to implement the program of National Basic Public Health Services (NBPHS), aiming to provide free and voluntary basic health services for all Chinese residents. This government-fund program has improved access to and affordability of primary health care [3]. According to the National Standard for NBPHS, grassroots health institutions are the main providers of NBPHS, including village clinics, township health centers, and community health service centers. The two characteristics of NBPHS are free and voluntary.

The categories of NBPHS have been increasing in the past few years. The initial service package included nine categories: management of resident health records, health education, prophylactic vaccination, prevention of infectious diseases, health management of children, women, and the elderly, health management of patients with chronic diseases, management of patients with severe mental disorders. Subsequently, public health emergency management, health management of 
tuberculosis, and traditional Chinese medicine were added in 2017. Based on the National Standard for NBPHS, a total of 12 categories are included in the program, and almost everyone has access to the basic public health package[1].

In China, internal migrants have made significant contributions to economic growth [4]. However, they are more vulnerable to experience or perceive discrimination because of lower socioeconomic status [5-8]. Specifically, due to institutional barriers such as the Household Registration System (Hukou), they have difficult access to the achievement of equal rights to health services compared with residents [7, 9-11], which continues to prevent them from enjoying the equal benefits of social development [12].

The equalization of NBPHS can improve the disadvantaged position of internal migrants in health care. According to the National Standard for NBPHS (third edition), the first step in receiving relative services is to establish health records. Those who have lived under the jurisdiction within a region for more than six months are eligible to establish health records, despite where their Hukou is registered. For internal migrants, particularly, it is available to enjoy the NBPHS as long as they have lived under the jurisdiction within a region for more than six months.

Previous studies have found some benefits of NBPHS. For example, health inequality is alleviated [13], maternal mortality rate is reduced [14], and the elderly's physical health is improved [15]. Research on rural areas found that NBPHS could improve health consciousness among rural residents [16]. Moreover, it is associated with an increased volume of neonatal health services and reduced neonatal mortality [17]. For internal migrants, NBPHS can enhance their willingness for a long stay [18]. But the equalization of NBPHS is one of the hardest nuts to crack, and inequality for internal migrants exists in access to NBPHS [18]. However, few studies have examined the effect of national basic public health services on the health of internal migrants in China.

This paper explores whether NBPHS has improved the health of internal migrants to find positive effects through propensity score matching (PSM). Understanding the impact of heterogeneity is one of the purposes of this paper, and the improvement is significant for patients with hypertension and those between 35 and 65 years of age. It is found that the improvement is significantly smaller for patients with diabetes and those above 65 years of age. There is no statistically significant effect on those with both hypertension and diabetes.

\section{Methods}

\subsection{Data}

The data used in this study came from the 2017 China Migrants Dynamic Survey (CMDS), a nationally representative survey of migrants aged 15-59 [19,20], which was conducted by the National Health Commission of China. This database collected internal migrants' demographic characteristics, health status, self-reported health, and whether individuals have established health records. In this study, those who migrated less than six months were excluded as they are not qualified for NBPHS. The final sample included 150,384 observations, among which 45,240 internal migrants had health records while 105,144 internal migrants had no health records.

\subsection{Health outcome variables}

The outcome variables consist of two recognized measures of health status, including self-reported health, and whether you have been ill in the past year. Self-reported health is a four-point scale measurement from 1 (unhealthy) to 4 (very healthy). For the latter health indicator, the question is "have you been ill (injured) or unwell in the past year", and there are three choices: "Yes, the last one happened in two weeks", "Yes, the last one happened two weeks ago" and "No". The first two answers are summarized as having illness in the past year and equal to 1 . The third answer means no illness in the past year and equals 0 . 


\subsection{Core independent variables}

As previously noted, the establishment of health records is the basis for receiving the treatment of NBPHS. Thus, a binary variable of whether health records have been established was used to measure the enrollment.

The core independent variable in this study is a binary variable: whether health records have been established or not. In the CMDS, the question is "whether the health record has been established for you locally?", and there are four answers: (1) Yes, it has been established. (2) It has not been established and I never heard about it. (3) It has not been established but I've heard about it. (4) I'm not clear about it. The outcome variable of health records is a binary indicator that takes a value equal to 1 if individual reports to have established health records, otherwise, it is equal to 0 .

\subsection{Covariates}

The covariates can be divided into three categories: personal, household, and social characteristics. Personal characteristics include gender, hukou, age, migration time, marital status, education, range of migration, willingness of staying, migration reason, and career. Household and social characteristics include household income, the status of house property, the time needed to reach the nearest medical facility, the number of people living together, and the city level.

Hukou is a binary variable, equal to 1 if registered in the town, county, or other city levels; equal to 0 if registered in the countryside. Marital status is divided into three categories: not married, married, and divorced/widowed. Education is an ordered variable with seven dimensions: below elementary school, elementary school, middle school, high school/technical secondary school, junior college, undergraduate college, and graduate. Seven reasons for migration are included: migration for working, family (relocation, marriage, birth), friends (for help in some way), study, joining the army, providing for the aged, and other reasons. The range of migration is a variable with three categories: equal to 1 if across the county in the city, equal to 2 if across the city in the province, and equal to 3 if across the province. The willingness of staying is a binary variable that takes a value equal to 1 if migrants wish to remain in the locality and equal to 0 if else. There are seven categories of career and three categories of the city level as listed in Table 1.

Table 1 presents the descriptive statistics. On average, individuals with health records have better self-reported health and are less likely to get ill in the past year. Health outcomes differ significantly between the two groups. There are significant differences except for migration time, other migration reasons, and the career of businessmen. On average, enrolled internal migrants are older, with a higher probability of married, higher education, higher willingness of staying, more people living together, and lower household income. There are also several disparities for migration reasons, career, and regions.

\subsection{Empirical strategy}

While using non-experimental data, the matching method is one possible way to solve the selection problem that may lead to the selection of treatment [21]. Propensity scores match (PSM) is suggested to reduce multiple observable characteristics to a single dimension [22]. According to the pre-treatment characteristics, the basic idea is to find a large group of individuals in the control group who are similar to the individuals in the treatment group [21]. This means the pairing of treated and untreated internal migrants who are comparable but have different treatment statuses.

The propensity score was generated first, which implies the probability of having a health record that represents whether an individual can enjoy the NBPHS. Individuals whose propensity score is not in the range of propensity score were excluded in the subsequent research. According to previous studies, [12.23] the logit regression was used to estimate the probability of enrollment via the equation (1). 
$H R_{i}$ represents whether an individual has established health records, meaning whether the individual can be enrolled in NBPHS, $X_{p i}$ is a vector of personal characteristics, $X_{h \mathrm{i}}$ is a vector of household characteristics and $X_{s i}$ is a vector of social characteristics as depicted above.

\subsection{Matching algorithms}

Four different matching algorithms of PSM were used to ensure the robustness of the results. First, 1:1 and 1:4 nearest neighbor (NN) matching with replacement was used in this study, which means that the closest one and four partners are chosen from the comparison group to match a treated individual, respectively. Second, radius matching was used, where the basic idea is to use all of the members from the control group within the radius, and more individuals can be used for matching to help avoid the risk of poor matching [24]. In the present study, the caliper is set at 0.1 for each treated individual, and this study selected matched individuals from $10 \%$ differences of propensity scores. Third, the results of kernel matching (KM) were also reported in this study. By using kernel matching, the counterfactual outcome was constructed using weighted averages of all members in the control group. More information is used and its advantage is the lower variance [21].

\section{Results}

\subsection{Determinants of having health records}

Table 2 reports the propensity score. Those who have established heath records are more likely to have house property, to have local Hukou, to have married, to have higher education, to have more people living together, to have a higher probability of working as a manager, service worker, professional and agricultural worker. Moreover, females, with urban Hukou, higher educational background, stronger willingness of staying, a smaller range of migration, migration reasons for family, friends and providing for the aged, and those who work as managers, professionals, service workers, and agricultural workers have a higher probability of enrollment. From the perspective of family characteristics, internal migrants who have house property, lower time to get to the nearest health facility, more family members living together have a significantly higher probability of enrollment, while the impact of household income is extremely lower. The probability of enrollment is significantly lower for those living in megacities compared to other cities. Additionally, no significant differences were found between the treatment group and the control group in age, migration time, time to get to the nearest health facility, and whether to live in other cities.

\subsection{Propensity score}

Figure 1 presents the distribution of propensity scores and the common support area. In the sample, most internal migrants with health records (treated) have a suitable match. "Treated: off support" and "Untreated: off support" indicate no appropriate match for internal migrants, which were excluded from the estimation.

Figure A1 in the supplementary file shows the mean standard deviation for each covariate. It can be observed that there are significant differences between the treatment group and the control group before matching.

Table A1 in the supplementary file shows the balance test. After matching, the mean standard deviation for each covariate decreased below the standard threshold of 5\% [21]. The overall bias in the unmatched group was $6.7 \%$ and the value was $0.5 \%$ in the matched group. The overall bias decreased by $90 \%$ after matching. Furthermore, Figure A2 presents the propensity score before and after matching, indicating that the propensity score between the two groups that matched was very similar. 


\subsection{Impact of NBPHS on internal migrants' health}

Table 3 presents the impact of NBPHS on internal migrants' health. The findings indicate that NBPHS has significantly improved the health of internal migrants. Results of PSM are shown in Columns 2-5, and four matching algorithms indicate the positive effects of NBPHS. Self-reported health is improved by 2.7 and 2.9 percentage points for 1:1 and 1:4 NN matching (Panel A, column 2-3). Both radius and kernel matching show similar results, with an increase in self-reported health by 2.8 and 2.9 percentage points (Panel A, column 4-5), respectively. The probability of having an illness in the past year has decreased by 3.7 and 3.5 percentage points for 1:1 and 1:4 NN matching (Panel B, column 2-3). ATT has the same value as radius and kernel matching, and NBPHS has reduced the probability of having illness in the past year by 3.3 percentage points (Panel B, column 4-5).

\section{4 heterogeneity}

This study evaluates the impact of NBPHS on the health of patients with hypertension and diabetes, patients with both hypertension and diabetes because health management services for patients with hypertension and diabetes are an important part of NBPHS. The results are presented in Table 4, and for patients with hypertension, NBPHS significantly improved self-reported health by 8.3 percentage points and reduced the probability of having illness in the past year by 6.6 percentage points. However, for patients with diabetes, NBPHS improved self-reported health by 11.9 percentage points and reduced the probability of having illness in the past year by 2 percentage points, which were statistically insignificant. Column 3 shows the impact on patients with both hypertension and diabetes, indicating that the impact did not reach statistical significance for these individuals.

Table 4 also presents the impact of NBPHS on internal migrants of different ages. The results are shown in Columns 4-6, revealing that the impact on those between 15 and 35 years old is similar to those between 35 and 65 years old. This implies that NBPHS has significantly improved self-reported health and reduced the probability of having illness in the past year. However, for internal migrants over 65 years old, no clear evidence of significant improvement was found in both health indicators.

\section{Discussion}

This study first estimates the probability of enrolling in NBPHS for internal migrants in China. It is found that those who have married, with higher education, stronger willingness of staying, and more people living together have a higher probability of enrollment. Access to NBPHS varies among internal migrants with different characteristics, and influencing factors include residence, age, education, and housing property status.

Importantly, propensity score matching (PSM) was applied to estimate the causal effect of NBPHS on internal migrants' health. Similar results were found by means of different matching algorithms. The self-reported health improvement ranged from 2.7 to 2.9 percentage points, and the probability of having illness in the past year decreased from 3.7 to 3.5 percentage points. In general, NBPHS has a positive impact on the health of internal migrants.

It is critical to understand the heterogeneous impact as it explores which groups benefit more from NBPHS and which groups benefit less. In China, the treatment of hypertension is a national public health priority [25], but hypertension is common and its prevalence is rising, yet it remains inadequately controlled [26]. According to the National Standard for NBPHS (third edition), specific services for patients with hypertension include an annual free blood pressure measurement, lifestyle guidance, and an annual physical examination. Our findings indicate that NBPHS also effectively improves the health of internal migrants with hypertension. Similar to hypertension, China has witnessed a marked increase in the prevalence rate of diabetes $[26,27]$. For internal migrants with diabetes, a free fasting blood glucose test 4 times a year, an annual health examination, and medical advice are available according to the National Standard for NBPHS (third edition). This study found that NBPHS did not significantly improve the health of internal migrants with diabetes. Management of 
hypertension and diabetes is one of the major responsibilities of primary care providers [27], which is the main provider of NBPHS. Although the quality of primary health care in China is poorly characterized [28], the results of this research show that primary health care plays a positive role in improving the health of internal migrants with hypertension.

It can be found that NBPHS did not significantly improve the health of internal migrants with both hypertension and diabetes. For those who suffer from both chronic diseases, their health is worse than those with only one chronic disease. For example, hypertension brings about an increased risk of cardiovascular disease in patients with diabetes [29]. One possible explanation is that NBPHS mainly provides some primary health care, which may be insufficient for those in worse health, at the same time, more precise and effective diagnosis and treatment are needed.

Furthermore, this study found that the benefits of internal migrants vary from age to age. Specifically, for those above 65 years old, NBPHS did not significantly improve their health compared to those aged between 15 and 65 . The elderly over 65 are the key service groups of NBPHS, and specific service items include health assessment, physical examination, and health guidance that is given mainly through conversation. However, there are many dialects in China, and many elderly people only understand the local dialects not the dialects of other regions. The linguistic heterogeneity leads to not only inequality in healthcare but also a decline in the quality of healthcare information [28-30]. In particular, previous studies have suggested that language barriers have a significant and negative impact on the health status of Chinese internal migrants above 65 years old [31], which is consistent with our study. Language differences may have a negative impact on the effectiveness of NBPHS, resulting in no significant improvement in the health of internal migrants over 65.

This research is of great significance to promoting the development of basic public health services in China. One feature of NBPHS is to benefit all Chinese residents, including internal migrants. We find that internal migrants have benefited from it, suggesting that NBPHS has a positive role in promoting the fairness of health services. However, there is still room for improvement in the program. As the implementing agency of the program, the primary health institution has always the problem of insufficient capacity, which also affects the effectiveness of NBPHS. Moreover, medical staff in primary medical institutions are relatively older and usually speak dialects, which has an adverse effect on the elderly who have migrated from other regions. Therefore, encouraging more young doctors to provide health services in primary institutions and promoting the sinking of high-quality medical resources can further improve the quality of NBPHS.

This research has also some limitations as follows. First, due to data limitations, we cannot study internal migrants under 15 years old, and further efforts should be made to evaluate the impact of NBPHS on the health of children. Second, selfreported health, as a relatively subjective indicator, could be affected by the response bias. Although objective health measures are also applied, more health variables can be included in future studies.

\section{Conclusion}

The results show that NBPHS has significantly improved the health of internal migrants. Although NBPHS is designed to provide equal access to basic health services for all Chinese residents, gains are not shared equally. Therefore, policymakers should not only pay attention to the equalization of project implementation but also focus on narrowing the benefits gap between different groups of people. Also, it is urgent to use better quality medical resources to provide basic public health services and promote the sinking of high-quality medical resources.

\section{References}

1. Tao W, Zeng Z, Dang H, et al. Towards universal health coverage: Achievements and challenges of 10 years of healthcare reform in China. BMJ Glob Heal. 2020;5(3):1-10. doi:10.1136/bmjgh-2019-002087.

2. Reich MR, Harris J, Ikegami N, et al. Moving towards universal health coverage: Lessons from 11 country studies. Lancet. 2016;387(10020):811-6. doi:10.1016/S0140-6736(15)60002-2. 
3. Meng Q, Xu L, Zhang Y, et al. Trends in access to health services and financial protection in China between 2003 and 2011: A cross-sectional study. Lancet. 2012;379(9818):805-14. doi:10.1016/S0140-6736(12)60278-5.

4. Qin X, Pan J, Liu GG. Does participating in health insurance benefit the migrant workers in China? An empirical investigation. China Econ Rev. 2014;30:263-78. doi:10.1016/j.chieco.2014.07.009.

5. Zhang J, Li X, Fang X, Xiong Q. Discrimination experience and quality of life among rural-to-urban migrants in China: The mediation effect of expectation-reality discrepancy. Qual Life Res. 2009;18(3):291-300. doi:10.1007/s11136-0099454-6.

6. Peng BL, Zou GY, Chen W, Lin YW, Ling L. Association between health service utilisation of internal migrant children and parents' acculturation in Guangdong, China: A cross-sectional study. BMJ Open. 2018;8(1). doi:10.1136/bmjopen-2017018844.

7. Chen J. Internal migration and health: Re-examining the healthy migrant phenomenon in China. Soc Sci Med. 2011;72(8):1294-301. doi:10.1016/j.socscimed.2011.02.016.

8. Chen Y, Feng S. Access to public schools and the education of migrant children in China. China Econ Rev. 2013;26(1):75-88. doi:10.1016/j.chieco.2013.04.007.

9. Litzinger RA. Contesting Citizenship in Urban China: Peasant Migrants, the State, and the Logic of the Market. Am Ethnol. 2001;28(1):247-8. doi:10.1525/ae.2001.28.1.247.

10. Chen X, Stanton B, Kaljee L, et al. Social stigma, social capital reconstruction, and rural migrants in Urban China: A population health perspective. Hum Organ. 2011;70(1):22-32. doi:10.17730/humo.70.1.k76047734m703500.

11. Hou Z, Lin S, Zhang D. Social capital, neighbourhood characteristics and utilisation of local public health services among domestic migrants in China: A cross-sectional study. BMJ Open. 2017;7(8):1-10. doi:10.1136/bmjopen-2016014224.

12. Yao Q, Liu C, Sun J. Inequality in health services for internal migrants in China: A national cross-sectional study on the role of fund location of social health insurance. Int J Environ Res Public Health. 2020;17(17):1-22. doi:10.3390/ijerph17176327.

13. Zhang Z, Miao Y. Research on the Contribution of Basic Public Health Services to Residents' Health Differences (In Chinese). China Population Science. 2020;34(1):78-89.

14. Zhao P, Diao Y, You L, Wu S, Yang L, Liu Y. The influence of basic public health service project on maternal health services: An interrupted time series study. BMC Public Health. 2019;19(1):1-8. doi:10.1186/s12889-019-7207-1.

15. Hao X, Yang Y, Gao X, Dai T. Evaluating the effectiveness of the health management program for the elderly on healthrelated quality of life among elderly people in China: Findings from the China health and retirement longitudinal study. Int J Environ Res Public Health. 2019;16(1). doi:10.3390/ijerph16010113.

16. Liu J, Mao Y. Rural Resident Experience on National Basic Public Health Services. A Cross-Sectional Survey in 10 Western Provinces of China. Healthcare. 2019;7(4):160. doi:10.3390/healthcare7040160.

17. Zhao P, Han X, You L, Zhao Y, Yang L, Liu Y. Effect of basic public health service project on neonatal health services and neonatal mortality in China: A longitudinal time-series study. BMJ Open. 2020;10(7):1-6. doi:10.1136/bmjopen-2019034427.

18. Long $\mathrm{C}$, Tang $\mathrm{S}$, Wang $\mathrm{R}$, et al. The migrating mediators and the interaction associated with the use of essential public health services: a cross-sectional study in Chinese older migrants. BMC Geriatr. 2020;20(1):1-10. doi:10.1186/s12877020-01878-0.

19. Miao S, Xiao Y. Does acculturation really matter for internal migrants' health?Evidence from eight cities in China. Soc Sci Med. 2020;260:113210. doi:10.1016/j.socscimed.2020.113210.

20. Xia Y, Ma Z. Relative deprivation, social exclusion, and quality of life among Chinese internal migrants. Public Health. 2020;186:129-36. doi:10.1016/j.puhe.2020.05.038. 
21. Caliendo M, Kopeinig S. Some practical guidance for the implementation of propensity score matching. J Econ Surv. 2008;22(1):31-72. doi:10.1111/j.1467-6419.2007.00527.x.

22. Rosenbaum PR, Rubin DB. The central role of the propensity score in observational studies for causal effects. Matched Sampl Causal Eff. 1983;(1083):170-84. doi:10.1017/CB09780511810725.016.

23. Pulok MH, van Gool K, Hall J. Inequity in healthcare use among the indigenous population living in non-remote areas of Australia. Public Health. 2020;186:35-43. doi:10.1016/j.puhe.2020.06.051.

24. Bagnoli L. Does health insurance improve health for all? Heterogeneous effects on children in Ghana. World Dev. 2019;124:104636. doi:10.1016/j.worlddev.2019.104636.

25. Chen Z. Launch of the health-care reform plan in China. Lancet. 2009;373(9672):1322-4. doi:10.1016/S01406736(09)60753-4.

26. Lu J, Lu Y, Wang X, et al. Prevalence, awareness, treatment, and control of hypertension in China: data from 1.7 million adults in a population-based screening study (China PEACE Million Persons Project). Lancet. 2017;390(10112):254958. doi:10.1016/S0140-6736(17)32478-9.

27. Mao W, Yip CMW, Chen W. Complications of diabetes in China: Health system and economic implications. BMC Public Health. 2019;19(1):1-11. doi:10.1186/s12889-019-6569-8.

28. Li X, Lu J, Hu S, et al. The primary health-care system in China. Lancet. 2017;390(10112):2584-94. doi:10.1016/S01406736(17)33109-4.

29. Ferrannini E, Cushman WC. Diabetes and hypertension: The bad companions. Lancet. 2012;380(9841):601-10. doi:10.1016/S0140-6736(12)60987-8.

30. Liang X, Chen J, Liu Y, He C, Li T. The effect of hypertension and diabetes management in southwest china: A beforeAnd after-intervention study. PLoS One. 2014;9(3):1-7. doi:10.1371/journal.pone.0091801.

31. Lu S, Chen S, Wang P. Language barriers and health status of elderly migrants: Micro-evidence from China. China Econ Rev. 2019;54:94-112. doi:10.1016/j.chieco.2018.10.011.

\section{Tables}

Table 1. Descriptive statistics 
Variable

Enrolled

Not enrolled

Difference

Mean Std. Dev. Mean Std. Dev. Mean Diff t-stat

\section{Health outcomes}

Self-reported health

3.805

0.462

3.783

0.483

$0.022^{\star * *}$

8.367

Illness in the past year

0.476

0.499

0.507

0.500

$-0.031^{\star \star *}$

10.906

Personal characteristics

\begin{tabular}{|c|c|c|c|c|c|c|}
\hline Gender & 0.496 & 0.500 & 0.522 & 0.500 & $-0.027 * \star \star$ & -9.448 \\
\hline Hukou & 0.249 & 0.433 & 0.225 & 0.418 & $0.024^{\star \star \star}$ & 10.138 \\
\hline Age & 37.111 & 11.029 & 36.971 & 10.998 & $0.141^{* \star}$ & 2.277 \\
\hline Migration time & 6.924 & 5.964 & 6.949 & 6.080 & -0.025 & -0.743 \\
\hline Marital status: not married & 0.116 & 0.321 & 0.144 & 0.351 & $-0.028 * \star \star$ & -14.296 \\
\hline Marital status: married & 0.829 & 0.377 & 0.798 & 0.401 & $0.030 * \star \star$ & 13.728 \\
\hline Marital status: divorce & 0.017 & 0.130 & 0.019 & 0.136 & $-0.002^{\star \star}$ & -2.485 \\
\hline Education & 3.512 & 1.161 & 3.428 & 1.173 & $0.084^{\star \star \star}$ & 12.796 \\
\hline Migration reason :for job & 0.833 & 0.373 & 0.865 & 0.342 & $-0.032^{\star \star \star}$ & -16.411 \\
\hline Migration reason: for family & 0.142 & 0.349 & 0.115 & 0.319 & $0.027 * \star \star *$ & 14.794 \\
\hline Migration reason: for friends & 0.009 & 0.097 & 0.008 & 0.089 & $0.002^{\star \star \star}$ & 2.941 \\
\hline Migration reason: provide for the aged & 0.009 & 0.093 & 0.006 & 0.074 & $0.003^{\star * *}$ & 7.035 \\
\hline Migration reason: other reasons & 0.007 & 0.085 & 0.007 & 0.082 & 0.000 & 1.001 \\
\hline Career: managers & 0.008 & 0.091 & 0.004 & 0.064 & $0.004^{\star * \star}$ & 10.405 \\
\hline Career: businessmen & 0.203 & 0.402 & 0.207 & 0.405 & -0.004 & -1.622 \\
\hline Career: professionals & 0.081 & 0.272 & 0.075 & 0.263 & $0.006^{\star \star *}$ & 3.768 \\
\hline Career: service staffs & 0.085 & 0.279 & 0.075 & 0.263 & $0.011 * \star \star$ & 6.976 \\
\hline Career: agricultural workers & 0.018 & 0.132 & 0.015 & 0.123 & $0.002^{\star \star \star}$ & 3.488 \\
\hline Career: manufacture staffs & 0.074 & 0.262 & 0.083 & 0.276 & $-0.009 * \star \star$ & -5.633 \\
\hline Career: other careers & 0.531 & 0.499 & 0.542 & 0.498 & $-0.011 * \star \star$ & -3.77 \\
\hline Range of migration & 2.196 & 0.764 & 2.347 & 0.750 & $-0.151 * \star \star$ & -35.634 \\
\hline Willingness of staying & 0.865 & 0.342 & 0.828 & 0.377 & $0.037 * \star \star$ & 17.769 \\
\hline \multicolumn{7}{|l|}{ Household characteristics } \\
\hline Household income & $6,959.128$ & $5,152.345$ & $7,357.872$ & $6,115.269$ & $-398.744 * \star \star$ & -12.138 \\
\hline House property & 0.259 & 0.438 & 0.216 & 0.412 & $0.043^{\star \star \star}$ & 18.143 \\
\hline Time to the nearest health Facility & 1.163 & 0.423 & 1.192 & 0.452 & $-0.029 \star \star \star$ & -11.714 \\
\hline The number of living together & 3.219 & 1.138 & 3.165 & 1.195 & $0.053^{\star \star \star}$ & 8.068 \\
\hline
\end{tabular}

Social characteristics 


\begin{tabular}{llllllc} 
Cities level: mega cities & 0.177 & 0.382 & 0.267 & 0.442 & $-0.09 * * \star$ & -37.492 \\
\hline Cities level: metropolis & 0.202 & 0.401 & 0.196 & 0.397 & $0.006 * \star \star$ & 2.786 \\
\hline Cities level: other cities & 0.621 & 0.485 & 0.537 & 0.499 & $0.083^{\star \star \star}$ & 29.982 \\
\hline Observations & 45,240 & & 105,144 & & &
\end{tabular}

Notes: ${ }^{*} p<0.1, * \star p<0.05, * \star * p<0.01$.

Table 2. Probabilityf enrollment 


\begin{tabular}{|c|c|c|}
\hline Variables & Coef. & Std. Dev. \\
\hline \multicolumn{3}{|l|}{ Personal characteristics } \\
\hline Gender & $-0.085^{\star \star *}$ & $(0.012)$ \\
\hline Hukou & $0.115^{\star \star \star}$ & $(0.014)$ \\
\hline Age & 0.001 & $(0.001)$ \\
\hline Migration time & -0.001 & $(0.001)$ \\
\hline Marital status: not married & $-0.211^{\star \star \star}$ & $(0.036)$ \\
\hline Marital status: married & $0.076^{\star \star}$ & $(0.030)$ \\
\hline Marital status: divorce & -0.077 & $(0.052)$ \\
\hline Education & $0.088^{\star \star *}$ & $(0.006)$ \\
\hline Migration reason: job & 0.004 & $(0.068)$ \\
\hline Migration reason: family & $0.182^{\star \star \star}$ & $(0.069)$ \\
\hline Migration reason: friends & $0.208^{\star *}$ & $(0.090)$ \\
\hline Migration reason: provide for the aged & $0.369^{\star \star *}$ & $(0.096)$ \\
\hline Career: manager & $0.555^{\star \star \star}$ & $(0.073)$ \\
\hline Career: businessmen & $0.041^{\star \star *}$ & $(0.015)$ \\
\hline Career: professionals & $0.101^{\star \star \star}$ & $(0.023)$ \\
\hline Career: service staffs & $0.221^{\star \star \star}$ & $(0.022)$ \\
\hline Career: Agricultural workers & $0.200^{\star * *}$ & $(0.045)$ \\
\hline Career: Manufacturing staffs & $0.074^{\star \star *}$ & $(0.022)$ \\
\hline Range of migration & $-0.157^{\star \star \star}$ & $(0.008)$ \\
\hline Willingness of Staying & $0.252^{\star \star \star}$ & $(0.016)$ \\
\hline \multicolumn{3}{|l|}{ Household characteristics } \\
\hline Household income & $-0.000^{\star \star \star}$ & $(0.000)$ \\
\hline House property & $0.090^{\star \star *}$ & $(0.014)$ \\
\hline Time to get to the nearest health facility & $-0.143^{\star \star \star}$ & $(0.013)$ \\
\hline The number of living together & $0.016^{\star * *}$ & $(0.006)$ \\
\hline \multicolumn{3}{|l|}{ Social characteristics } \\
\hline Cities level: mega cities & $-0.377^{\star \star \star}$ & $(0.018)$ \\
\hline Cities level: other cities & $0.087^{\star \star \star}$ & $(0.015)$ \\
\hline Cons & $-0.898^{\star \star *}$ & $(0.091)$ \\
\hline
\end{tabular}


Notes: ${ }^{\star} p<0.1,{ }^{\star \star} p<0.05,{ }^{\star \star \star} p<0.01, N=150384$, pseudo R- sq=0.017, Standard errors in brackets.

Table 3. Impact of NBPHS on health outcomes

\begin{tabular}{|c|c|c|c|c|}
\hline \multicolumn{5}{|c|}{ PSM } \\
\hline & $\mathrm{NN}(1 \otimes 1)$ & $\mathrm{NN}(1 \rrbracket 4)$ & Radius & Kernel \\
\hline & $(1)$ & $(2)$ & (3) & $(4)$ \\
\hline \multirow[t]{2}{*}{ Panel A. Self-reported health } & $0.027^{\star \star \star}$ & $0.029^{\star \star \star}$ & $0.028^{\star \star \star}$ & $0.029^{\star \star \star}$ \\
\hline & $\llbracket 0.004 \rrbracket$ & $(0.003)$ & $(0.003)$ & $(0.003)$ \\
\hline \multirow[t]{2}{*}{ Panel B. Illness in the past year } & $-0.037^{\star \star \star}$ & $-0.035^{\star \star \star}$ & $-0.033^{\star \star \star}$ & $-0.033^{\star \star \star}$ \\
\hline & $\varangle 0.004 \rrbracket$ & $(0.003)$ & $(0.003)$ & $(0.003)$ \\
\hline Observations & 150379 & 150379 & 150379 & 150379 \\
\hline
\end{tabular}

Notes: ${ }^{*} p<0.1,{ }^{*} p<0.05,{ }^{* \star} p<0.01$. Column 1 report the coefficients of OLS regression. Column 2-5 report ATT of PSM. Column 2-3 are 1:1 and 1:4 nearest neighbor matching, column 4-5 are Radius and Kernel matching respectively. Standard errors are shown in parentheses.

Table 4. Impact of heterogeneity

Hypertensive Diabetic $\quad \begin{aligned} & \text { Hypertensive\& } \\ & \text { Diabetic }\end{aligned} \quad 15 \leq$ age $<35 \quad 35 \leq$ age $<65 \quad$ age $\geq 65$

\begin{tabular}{|c|c|c|c|c|c|c|}
\hline & $(1)$ & (2) & (3) & (4) & (5) & (6) \\
\hline \multirow{2}{*}{$\begin{array}{l}\text { Panel A. } \\
\text { Self-reported } \\
\text { health }\end{array}$} & $0.083^{\star \star \star}$ & $0.119^{*}$ & 0.114 & $0.024^{\star \star \star}$ & $0.033^{\star \star \star}$ & 0.032 \\
\hline & $(0.027)$ & $(0.072)$ & $(0.093)$ & $(0.004)$ & $(0.006)$ & $(0.043)$ \\
\hline \multirow{2}{*}{$\begin{array}{l}\text { Panel B. } \\
\text { Illness in the } \\
\text { past year }\end{array}$} & $-0.066^{\star \star \star}$ & -0.02 & -0.01 & $-0.031^{\star \star \star}$ & $-0.031^{\star \star \star}$ & $-0.049^{\star}$ \\
\hline & $(0.017)$ & $(0.046)$ & $(0.052)$ & $(0.006)$ & $(0.005)$ & $(0.027)$ \\
\hline Observations & 6676 & 1086 & 810 & 71682 & 75682 & 3004 \\
\hline
\end{tabular}

\section{Figures}




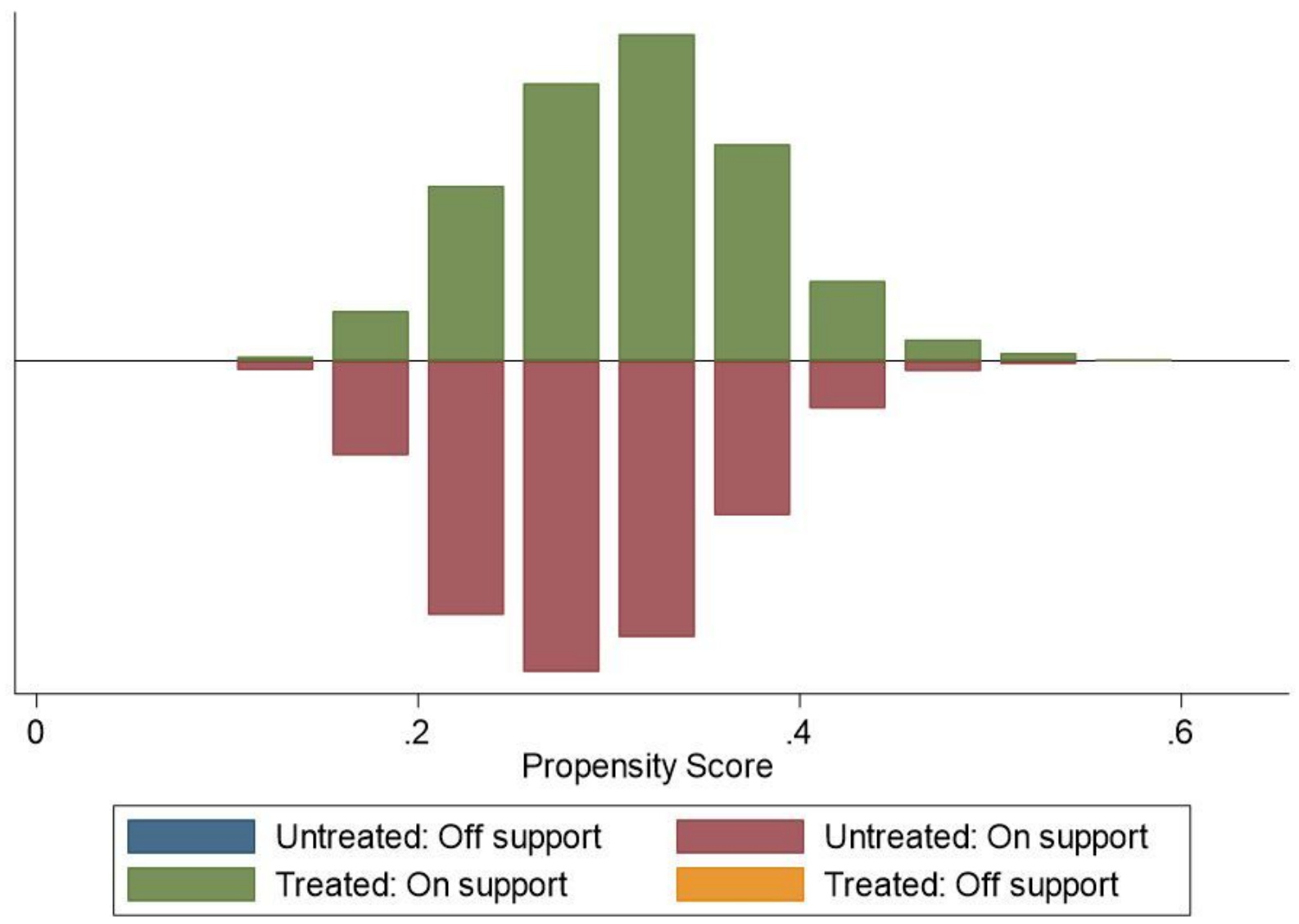

Figure 1

Common support area

\section{Supplementary Files}

This is a list of supplementary files associated with this preprint. Click to download.

- supplementaryfile.doc 